\title{
Quit and Win Wales: an evaluation of the 1990 pilot contest
}

\author{
Chris Roberts, Christopher Smith, John Catford
}

\begin{abstract}
Objective - To assess the effectiveness of the 1990 pilot Quit and Win contest held in South East Wales (UK) in reducing smoking prevalence.
\end{abstract}

Methods - Follow-up surveys of the 687 entrants were conducted after four months and one year through postal selfcompletion questionnaires. The questionnaires covered demographic background, smoking history, the methods used to quit, and the role of the contest in the quitting process. In addition, a short questionnaire was sent to a sample of those who did not enter the contest despite requesting an entry form.

Results - The data indicate a quit rate among participants of $30 \%$ at one year, and that other smokers were stimulated to quit, even though they did not formally enter the contest. Analysis of significant differences $(p<0.01)$ between successful and unsuccessful participants showed that the quitters tended to be older, to be heavier smokers, to have made fewer previous attempts to quit, to have stopped smoking straight away rather than to have cut down gradually, and to have received more support from their family and friends. Four-fifths of the non-quitters expressed an interest in a future contest.

Conclusions - Quit and Win contests appear to be a cost-effective approach to smoking cessation initiatives in Wales, though they need to be supported by more intensive methods to help the most resistant group of smokers who would like to give up. A number of refinements are recommended to improve impact in any future contest.

(Tobacco Control 1993; 2: 114-119)

Health Promotion Wales, Ffynnon-las, Ty Glas Avenue, Llanishen, Cardiff CF4 5DZ Wales, UK C Roberts

C Smith

Institute for Health Promotion, Ffynnonlas, Ty Glas Avenue, Llanishen, Cardiff CF4 5DZ Wales, UK $\mathrm{J}$ Catford
Wales". ${ }^{2}$ It is estimated that 4200 men and 1600 women die annually from smokingrelated diseases, and that the hospital costs to the National Health Service (NHS) in Wales in treating smoking-related illness total some $£ 27 \mathrm{M}$ per annum. Smoking prevention thus remains high on the agenda of health promotion workers, as witnessed by the targets set in the Health for All in Wales strategy for a continued decline in the level of smoking. ${ }^{3}$

A wide variety of smoking cessation programmes are available to those wishing to quit tobacco smoking, such as self-help leaflets and books, counselling from health professionals, stop-smoking groups, and a range of specific treatments including drugs and acupuncture. ${ }^{4}$ In addition to these strategies, which deal mainly with small groups or individuals, are mass media initiatives which have the potential for reaching large audiences cost effectively. One such initiative is the Quit and Win contest. This paper is concerned with a pilot Quit and Win contest run by Heartbeat Wales, the first national demonstration programme for heart disease prevention in the United Kingdom (UK). Results from four-month and one-year follow-up surveys of participants and a survey of non-participants are used to evaluate the long-term effectiveness of the contest.

\section{QUIT AND WIN : THE BACKGROUND}

The Quit and Win contest was first developed as a smoking cessation strategy by workers on the Minnesota Heart Health Programme in 1982 , and has since been incorporated into programmes developed to reduce smoking prevalence elsewhere in the USA and in European countries such as Finland, Sweden, and England. ${ }^{5-10}$ Quit rates achieved at 30-day follow-up have exceeded $60 \%$, while rates in excess of $20 \%$ have been recorded at six- and 12-month follow-ups. This suggests that, although there is a fall in the proportion of successful quitters over time, Quit and Win contests can be effective in the longer term.

Whilst Quit and Win contests may vary according to the specific needs of smokingcessation programmes in various locations, certain key features appear to be common to all contests. Firstly, Quit and Win contests use community-based mass media to attract as many participants as possible. As a result entrants are less likely to feel isolated in their attempt to quit, with potential support not only from family and friends but also from a 
large number of fellow participants. The public nature of the contest can also provide wider social encouragement to quit. A second key element is the incentive offered in the form of a prize draw, into which successful participants are entered. Attractions such as holidays are offered, often complemented by numerous smaller prizes. These can offset, or compensate for, the stress often involved in attempting to quit smoking. Thirdly, participants are usually asked to give up tobacco by a specific date and remain abstinent for a period of around 30 days, the contest thus covering the period when most relapses are thought to occur. ${ }^{11}$

\section{HEARTBEAT WALES' NO-SMOKING}

INTERVENTION

Since its inception in 1985, the Heartbeat Wales programme has initiated a number of no-smoking interventions and collaborated closely with a range of partners and other agencies undertaking smoking education to promote a smoke-free Wales. ${ }^{3,12}$ Initiatives targetted at young people have included "Smokebusters Wales", a young peoples club with activities to encourage non-uptake of smoking, and the further development of smoking education programmes and policies in schools. Amongst those initiatives targetted at the adult population are schemes promoting healthy environments, such as the "Heartbeat", "Healthy Hospital", and "Make Health Your Business" awards, which encourage smoke-free areas in public eating places, hospitals, and workplaces, respectively; media initiatives such as National No-Smoking Day and the production of a six-part television series "Don't Break Your Heart" which provided smoking cessation advice; and the enhancement of personal education for existing smokers through mechanisms such as primary health care and occupational health services.

Given the success of Quit and Win contests elsewhere, Heartbeat Wales decided to add to the above initiatives by implementing a pilot contest "Quit Tobacco: Head for Tobago" in an area of South Wales encompassing the counties of Gwent, Mid- and SouthGlamorgan. These three counties have a population of approximately $850000 \quad 18$ to 64-year-olds. A survey undertaken in 1990 indicated that $33 \%$ of this population smoked at least occasionally. In addition, this research showed that $62 \%$ of the smokers wished to give up and that $35 \%$ had made a serious attempt to do so in the last year. ${ }^{13}$

\section{Methods}

The total cost of the contest was $£ 44000$, which covered the consultancy fee $(£ 15000)$ for the public relations company which dealt with the day-to-day running of the scheme, advertising ( $£ 9700)$, design and distribution of entry forms $(£ 8800)$, the provision of a telephone line from which entry forms could be obtained ( $£ 2050)$, and a variety of other expenses associated with the running of the contest $(£ 8450)$. Smokers were free to enter the contest any time between 10 May and 1 August 1990, and had to remain abstinent for a period of one month to be entered into the grand prize draw. Numerous prizes were provided by a variety of sponsors, representing both local and national organisations. A prize draw number was given to each entrant for each month of participation. After a series of monthly draws, the final draw for the grand prize, a holiday in the Caribbean, was held. All prospective winners were given a cotinine saliva test prior to being presented with their prize to confirm their non-smoking status.

Entry forms could be obtained from numerous sources including local newspapers, dentists, general practices, pharmacists and shops, through letterbox drops, and by ringing the telephone number set up for the contest. The contest was publicised through the use of advertisements and press releases for the local commercial radio station, and national and local newspapers.

The evaluation of the contest was undertaken by means of four-month and one-year follow-up postal surveys of all participants and a four-month follow-up postal survey of 200 randomly selected non-participants (those requesting an entry form via the telephone number provided but failing to enter the contest). In total, 687 registered participants entered the contest. At the four-month evaluation $439(64 \%)$ returned self-completion questionnaires after two reminders, as did 99 $(50 \%)$ of the non-participants. At the one-year follow-up, $412(60 \%)$ participants returned questionnaires.

As table 1 indicates, responders to both participant surveys were representative of all contest participants in terms of sex. However, there was a statistically significant difference with respect to age; 18 - to 24-year-olds were under-represented among responders in both these surveys. It was not possible to assess the representativeness of responders to the nonparticipants survey, due to a lack of information on the non-responders.

The analysis presented here draws on information from all three surveys. A successful quitter is defined as someone who reported abstinence for the whole year after entering the contest. Differences between quitters, nonquitters, and non-participants were tested using either the Chi-square statistic $\left(\chi^{2}\right)$ or ttests for means or proportions; $p$-values of less

Table 1 Distribution of competition participants and survey respondents by sex and age (\%)

\begin{tabular}{lccc}
\hline Variable & $\begin{array}{c}\text { All participants } \\
(n=687)\end{array}$ & $\begin{array}{c}4 \text { month } \\
(n=439)\end{array}$ & $\begin{array}{c}1 \text { year } \\
(n=412)\end{array}$ \\
\hline Sex: & & & \\
$\quad$ Male & 52 & 53 & 54 \\
$\quad$ Female & 48 & 47 & 46 \\
Age group: & & & \\
18-24 & 14 & $9 \star \star$ & $7^{\star \star}$ \\
$25-34$ & 26 & 23 & 24 \\
$35-44$ & 22 & 24 & 23 \\
$45-54$ & 21 & 23 & 22 \\
$55-64$ & 11 & 13 & 15 \\
$65+$ & 6 & 8 & 9 \\
\hline
\end{tabular}

$\star \star \mathrm{p} \leqslant 0.01, \mathrm{t}$-test on proportions.

NB Small numbers for whom we have missing values were omitted from the analysis. 
than $0.05(5 \%)$ and $0.01(1 \%)$ are noted in the text and tables where appropriate.

\section{Results}

PARTICIPANTS

Quit rate

At the four-month follow-up survey, 266 $(61 \%)$ of the respondents claimed to have given up smoking. Eight months later 203 (49\%) reported continuous abstinence for the whole year, and are referred to subsequently in this paper as "quitters". The vast majority of them $(88 \%, \mathrm{n}=172)$ did not think they would resume smoking in the future. A further 25 respondents at one-year follow-up were not currently smoking but said they had smoked at some point in the year. Given its small size and the fact that this group did not report abstinence for the whole 12 months, they have been classified as non-quitters for the purposes of the analysis below. The remaining 184 people at the one-year follow-up were current smokers, of whom $148(80 \%)$ smoked "regularly" and $36(20 \%)$ "occasionally".

Characteristics of quitters and non-quitters Similar proportions of male $(52 \%)$ and female $(46 \%)$ respondents, and of non-manual workers (Social groups 1, 2 and 3 nonmanual) ${ }^{\star}(47 \%)$ and manual workers (Social groups 3 manual, 4 and 5) (49\%) were successful quitters at one year. However, there were statistically significant differences $(p<$ 0.01 ) in quit rates with age. These increased from $18 \%$ for respondents aged 18-24 to $47 \%$ for those aged between 25 and 54, and to $60 \%$ and $71 \%$ for those aged 55-64 and 65 and above, respectively.

In order to examine further differences between quitters and non-quitters in terms of their smoking history, reasons for entering the contest, and methods used in attempting to give up, data are drawn from questions included at the four-month follow-up. The analysis in the remainder of this section is thus based on the 179 quitters and 165 non-quitters who responded to the four-month survey.

Table 2 shows that heavier smokers and those having made fewer attempts to give up

Table 2 Quit status by smoking characteristics prior to the contest

\begin{tabular}{|c|c|c|}
\hline & $\%$ Quitting & $n$ \\
\hline $\begin{array}{l}\text { Cigarettes smoked daily: } \star \star \\
\text { Less than } 16 \\
16 \text { to } 20 \\
\text { More than } 20\end{array}$ & $\begin{array}{l}44 \\
46 \\
66\end{array}$ & $\begin{array}{l}112 \\
108 \\
108\end{array}$ \\
\hline $\begin{array}{l}\text { Previous quit attempts: }{ }^{\star \star} \\
2 \text { or less } \\
3 \text { or more }\end{array}$ & $\begin{array}{l}64 \\
36\end{array}$ & $\begin{array}{l}187 \\
144\end{array}$ \\
\hline $\begin{array}{l}\text { How long smoked for: } \\
\text { Less than } 20 \text { years } \\
20 \text { or more years }\end{array}$ & $\begin{array}{l}48 \\
55\end{array}$ & $\begin{array}{l}148 \\
189\end{array}$ \\
\hline
\end{tabular}

* As defined by the Office of Population Censuses and Surveys, UK, (1980). prior to the contest reported greater success in quitting. The length of time smoked prior to the contest does not appear to have had a significant impact on the quit rate. Quitters and non-quitters most commonly reported hearing about the contest through the local newspaper ( $21 \%$ of both). Friends and relatives $(17 \%$ and $14 \%)$ and dentists and doctors $(17 \%$ and $13 \%$ ) also proved to be important sources for bringing the contest to the attention of both groups. One difference found between the two groups was that a significantly higher proportion $(\mathrm{p}<0.05)$ of non-quitters $(15 \%)$ than quitters $(7 \%)$ had heard of the contest on the local radio station.

Entry forms were obtained from a wide variety of sources, particularly from doctors' surgeries and health centres $(22 \%$ of quitters and $15 \%$ of non-quitters), the Heartbeat Wales and Quit and Win contest offices $15 \%$ and $10 \%$ ), friends and relatives (14\% of both) and letterbox drops $(14 \%$ and $15 \%)$. One significant difference $(p<0.01)$ observed between the two groups was that a greater proportion of non-quitters $(15 \%)$ than quitters ( $3 \%$ ) obtained their entry form by ringing the telephone number which was set up.

Table 3 shows that the most common reason for entering the contest amongst both quitters and non-quitters was to stop smoking, followed by the chance to win one of the prizes on offer. Non-quitters were more likely to say they entered the contest to cut down smoking and to see how long the quit attempt could last, but this could reflect some post hoc justification of their lack of success in giving up.

The importance attached to the Quit and Win contest itself in the decision to quit differed significantly $(p<0.01)$ between the two groups; a greater proportion of quitters $(52 \%)$ than non-quitters $(44 \%)$ stated that it was a "very important" factor in their decision.

Participants were asked which methods they had used in their attempts to give up smoking since the contest started. As can be seen from table 4 , by far the most popular method utilised by quitters was will power/self motivation. This was followed by encouragement from family and friends, and a philosophy of taking each day as it came. These methods were also among the four most frequently mentioned by non-quitters, though encouragement from family and friends was mentioned significantly less often by the non-quitters. Indeed, when questioned further, a significantly $(p<0.01)$

Table 3 Reasons for entering the contest by quit status $(\%)$

\begin{tabular}{lcc}
\hline & $\begin{array}{c}\text { Quitter } \\
(n=179)\end{array}$ & $\begin{array}{c}\text { Non-quitter } \\
(n=165)\end{array}$ \\
\hline Stop smoking & 83 & 89 \\
Win a prize & 62 & 63 \\
Save money & 44 & 52 \\
Challenge & 40 & 38 \\
Encouraged/persuaded to & 30 & 28 \\
See how long could stop for & 21 & $34^{\star \star}$ \\
Cut down smoking & 12 & $25^{\star \star}$ \\
Charity/bet & 4 & 3 \\
\hline
\end{tabular}

$\star \star p \leqslant 0.01, \chi^{2}$ test.

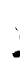

$\therefore$

5

$\therefore$

7

5

ner

2

\&:

$=$

$+$

$=$

$>$

4

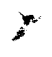

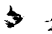

1

$=$

-

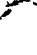

to

2

$-$

$=$

$\$$

$\hat{y}$

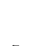

$x$

*:

-

$=$

$-$

$=$

$\approx$

$y=$

$\therefore$

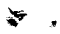

3 
Table 4 Methods used to give up smoking by quit status $(\%)$

\begin{tabular}{lcc}
\hline Method & $\begin{array}{c}\text { Quitter } \\
(n=179)\end{array}$ & $\begin{array}{c}\text { Non-quitter } \\
(n=165)\end{array}$ \\
\hline Will power/self motivation & 91 & 87 \\
Cut down gradually & 4 & $15 \star \star$ \\
Took each day as it comes & 46 & 40 \\
Nicotine gum (eg, Nicorette) & 4 & 2 \\
Stop-smoking tablets (eg, & 6 & 8 \\
Nicobrevin, Stoppers, & & \\
Stubbit) & 1 & 1 \\
Substitutes/herbal tobacco & 34 & 32 \\
Ate sweets/chewed gum & 49 & $38^{\star \star}$ \\
Encouraged by family/friends & 26 & 28 \\
Support from workmates & 3 & $9 \star$ \\
Joined group/clinic & 2 & 4 \\
Acupuncture/hypnosis & & \\
\hline$\star \mathrm{p} \leqslant 0.05, \chi^{2}$ test. & & \\
$\star \star \mathrm{p} \leqslant 0.01, \chi^{2}$ test. & &
\end{tabular}

lower proportion of non-quitters (45\%) than quitters $(61 \%)$ reported that family and friends had been very supportive. Further statistically significant differences in the methods used by the two groups relate to cutting down gradually and joining smoking cessation groups or clinics, both of which were cited more often by the non-quitters.

Persons unable to quit

The most common length of abstinence for the 209 participants unsuccessful in quitting for the whole year was up to one month $(32 \%, n$ $=62)$, with a further $41 \%(\mathrm{n}=80)$ starting smoking before four months had elapsed. The major reasons given for starting to smoke again were stress $(40 \%, \mathrm{n}=79)$ and enjoyment of smoking $(21 \%, n=42)$. Other reasons cited included putting on weight $(10 \%, \mathrm{n}=19)$ and a lack of support from family and friends $(10 \%, n=19)$. In terms of the number of quit attempts made during the year, the vast majority of unsuccessful respondents reported one or two attempts $(68 \%, \mathrm{n}=132)$, with a fifth trying three or four times $(21 \%, n=41)$.

Future intentions of unsuccessful entrants At the one-year follow-up, the 184 participants who reported that they were currently smoking were questioned as to whether they would make a further attempt to quit again in the future. Nearly all, $82 \%(n=149)$, claimed they would; $2 \%(n=4)$ thought they would not be attempting to quit in the future, while $16 \%(n=28)$ were undecided. When asked about their chances of success in quitting in the future, $69 \%(n=122)$ believed this to be at least "fair" but $19 \%(n=34)$ thought it was "poor".

Finally the unsuccessful entrants were asked whether they would take part in a future Quit and Win contest. At the four-month followup, $79 \%(n=136)$ thought they would be "fairly likely" or "very likely" to enter, compared with $68 \%(n=123)$ at the one-year follow-up.

NON-PARTICIPANTS

The 99 non-participants were of similar age and smoking history to the participants but significantly $(\mathrm{p}<0.01)$ more of them were women $(62 \%$ compared to $47 \%)$. Nonparticipants were asked why they had not entered the contest despite requesting an entry form. Fifty percent $(n=48)$ reported that it was because they did not believe they could give up smoking. A further $26 \%(n=25)$ said that they had simply forgotten to enter. Amongst the other reasons cited were losing interest in the contest $(22 \%, \mathrm{n}=21)$ and the belief that the chances of winning a prize were limited $(19 \%, n=18)$. Since hearing of the Quit and Win contest, $51 \%(n=45)$ of nonparticipants had tried to give up smoking. Of those attempting to quit, $63 \% \quad(\mathrm{n}=30)$ reported that the contest had been a "fairly" or "very important" factor in making their decision to give up. Forty-two percent ( $\mathbf{n}=$ 22) reported that they had been successful in giving up, $64 \%(n=14)$ of whom did not believe that they would resume smoking again in the future.

Those non-participants who had not tried to quit or who had been unsuccessful in their attempts to do so since hearing of the contest were asked whether they would participate in a future Quit and Win contest. Seventy-eight percent $(n=56)$ reported that they would be "very" or "fairly likely" to enter such a contest. Furthermore, $96 \%(n=92)$ were of the opinion that, despite not entering the present contest, it was a "good" idea.

\section{Discussion}

The data preser.ted here show that Heartbeat Wales' Quit and Win contest resulted in an important and valuable rate of smoking cessation. The proportion of respondents to the one-year follow-up survey who reported quitting smoking was $49 \%$. Although these data are based on self-reported behaviour, previous research in Wales has indicated minimal under-reporting (less than $0.1 \%$ ) of smoking in surveys of prevalence. ${ }^{12}$

The majority of the quitters thought the contest had been a very important factor in their decision to give up and did not expect to resume smoking in the future. In addition, $39 \%$ of the non-quitters reported that they were smoking less than before entering the contest, while the widespread media coverage given to Quit and Win Wales is likely to have prompted other smokers to quit. This has been demonstrated by the survey of those registering an interest in the contest but not actually entering. Half of these non-participants had attempted to quit since hearing of Quit and Win, $63 \%$ of whom cited the contest as an important factor in their decision to give up.

In smoking-cessation programmes quit rates are conventionally measured as a proportion of the total number of participants rather than just of those who respond to follow-up enquiries. On this basis the quit rate for the contest reported here was $30 \%$ at one year. Direct comparison with other contests is problematic as point-prevalence quit rates are commonly reported, ${ }^{5,9}$ rather than the prolonged abstinence measure used in the present 
study. Indeed it could be argued that prolonged abstinence represents a more rigorous measure of success. With this in mind, the Welsh results appear to compare favourably with others obtained from Quit and Win contests elsewhere.$^{5-10}$ For example, in a recent UK Quit and Win contest, $21 \%$ of participants claimed not to be smoking at 12 months. ${ }^{10}$ The quit rates also compare favourably with other types of smoking-cessation interventions, such as advice from a family doctor, mass media advertising, and the creation of unpaid publicity in the media. ${ }^{14-15}$ Furthermore, whilst the estimated cost, using Townsend's method, of each year of life saved by the contest $(£ 42)$ is somewhat higher than that quoted for some of the other previously mentioned types of smoking cessation activities, it is lower than that reported for clinical interventions such as a coronary bypass operation. ${ }^{15}$

The data also show that success in quitting varied with the cessation strategy adopted, and in particular with whether smoking was stopped straight away or by cutting down gradually. Indeed unsuccessful participants were almost four times as likely as the successful ones to attempt to give up smoking by cutting down gradually, which supports previous observations that this particular strategy is inversely related to outcome. ${ }^{7}$ Also consistent with the literature were the findings which suggested that stress and a lack of support from friends and family were contributory factors in the failure to quit. ${ }^{7,8,16}$ Non-quitters most frequently mentioned stress as the reason for starting to smoke again, and they were significantly less likely than quitters to mention encouragement from friends and family as a method of smoking cessation and to perceive support from friends and family as very important in the quitting process.

Although the quit rates were comparatively high overall, the data show that the Quit and Win contest did not successfully engage all types of smoker. First, in comparison with other age groups, the quit rate achieved by the youngest respondents, the 18- to 24-year-olds, was low. When all participants aged 18 to 24 are included in the analysis and not just those who returned questionnaires, the quit rate after one year was $5 \%$ for the 18- to 24-yearolds whereas the equivalent figures for those aged 55-64 and 65 and over were $46 \%$ and $61 \%$, respectively. Low cessation rates by younger smokers have been noted elsewhere and remain of concern; recent research in Wales has shown that the decline in smoking prevalence between 1985 and 1990 was lowest amongst 18 - to 24-year-olds. ${ }^{1,17}$

Second, unsuccessful participants in the contest tended to be those with a history of smoking fewer cigarettes and of having made many previous attempts to quit. The former finding is somewhat surprising, since there is a general view that heavier rather than lighter smokers find it most difficult to stop..$^{14,18,19}$ The latter finding has been reported elsewhere ${ }^{17,18}$ and suggests that other approaches to smoking cessation, with a higher level of input from professionals, may be required for those who have previously made multiple unsuccessful attempts to quit. ${ }^{14,20}$ This will increase in importance over time as a "hard core" of smokers are left.

On balance, it would appear that Quit and Win contests can make a useful contribution to smoking prevention programmes. Whilst there is evidence from elsewhere to suggest that recruitment rates can decline with the frequency that contests are held, ${ }^{6}$ the favourable quit rate achieved in the pilot Quit and Win Wales contest, together with the fact that the majority of the unsuccessful entrants and the non-participants expressed an interest in participating in the future, has resulted in a contest covering the whole of Wales being planned for the near future.

In order to improve on the performance of the pilot contest and to enhance the enrollment figure, this all-Wales contest will need to take on board the findings presented here. In particular greater emphasis will need to be placed on targetting young smokers by presenting an upbeat image to attract them. The use of young contest spokespersons and an emphasis on fun events could be helpful, as could pre-testing any design work for publicising the contest with this age group. The contest should focus on those methods of smoking cessation which are associated with success, such as stopping completely rather than cutting down gradually, as well as suggesting ways of coping with stress. Greater attention should be given to involving family and friends and to developing other support mechanisms for participants, particularly for the early stages of cessation when relapse is most likely. Attempts should be made to maintain publicity throughout the period of the contest in order to avoid those requesting entry forms losing interest or forgetting to complete and return their forms. Finally, since most of the participants in the pilot contest heard about it through local sources, such as the press, their dentist or doctor, and their friends and relatives, a series of local contests culminating in an all-Wales grand prize draw would seem advisable.

We would like to thank Diane Wilde and Helen Pearson for fieldwork support; Sue Avery for her help in preparing this manuscript; and Laurence Moore for his helpful comments on an earlier draft of the paper.

1 Smith C, Catford J, Moore L. Recent trends in lifestyles in Wales 1985-1990. Heartbeat Wales Technical Reports No. 24. Cardiff: HPAW, 1992 .

2 Health Promotion Authority for Wales. The smoking epidemic: counting the cost in Wales. Cardiff: HPAW, 1991

3 Health Promotion Authority for Wales. Health for all in Wales. Plans for action $3:$ the agenda for 1992-94. Cardiff HPAW, 1992

4 Catford J, Woolaway M. Giving up smoking for life. In Smith A, eds. Recent advances in community medicine, No. 3 Edinburgh: Churchill Livingstone, 1985: 133-57.

5 Lando $H$, Loken B, Howard-Pitney B, Pechacek $T$. Community impact of a localised smoking cessation contest. Am F Public Health 1990; 80: 601-3.

6 Lando HA, Hellerstadt WL, Pirie PL, Fruetel J, Huttner P. Results of a long-term community smoking contest. $\mathrm{Am}$ Results of a long-term community smoki

7 Glasgow R, Klesges R, Mizes J, Pechacek T. Quitting smoking: strategies used and variables associated with success in a stop smoking contest. $\mathcal{F}$ Consult Clin Psychol 1985; 53 : 905-12. 
8 Lefebvre R, Cobb G, Goreczny A, Carleton R. Efficacy of an incentive-based community smoking cessation programme. Addict Behav 1990; 15: 403-11.

9 Elder J McGraw S, Rodrigues A, Lasater T, Ferreira A Kendall L, et al. Evaluation of two community-wide Kendall L, et al. Evaluation of two community-wide

10 Health Education Authority. Quit and Win 1990 UK evaluation summary. London: HEA, 1991.

11 US Department of Health and Human Services. Reducing the health consequences of smoking: 25 years of progress. Washington, DC; DHHS, 1989 (DHHS Publication No. (CDC) 89-8411)

12 Health Promotion Authority for Wales. The Heartbeat Wales no-smoking intervention. An empirical study of the economic viability of a health promotion programme. Heartbeat Wales Technical Report No. 22. Cardiff: HPAW, 1991.

13 Smith C, Moore L, Catford J. District Health Authorities in Wales: Recent trends in lifestyles 1985-1990. Heartbeat Wales Technical Report No. 25. Cardiff: HPAW, 1992.

14 Lennox AS. Determinants of outcome in smoking cessation. Br F Gen Pract 1992; 42: 247-52.
15 Reid D, Smith N. What is the single most important intervention for the prevention of smoking-related disease? In: Durston B, Jamrozik, eds. Tobacco and Health 1990. The global war. Proceedings of the Seventh World Conference on Tobacco and Health. East Perth: Health Department of Western Australia; 309-13.

16 Mermelstein R, Lichtenstein E, McIntyre K. Partner support and relapse in smoking cessation programs. $\mathscr{J}$ Consult Clin Psychol 1983; 15:465-6.

17 Coambs $\mathrm{R}, \mathrm{Li} \mathrm{S}$, Kozlowski LT. Age interacts with heaviness of smoking in predicting success in cessation of smoking. Am f Epidemiol 1992; 135: 240-6.

18 Hellman R, Cummings KM, Haughey BP, Zielezny MA, O'Shea RM. Predictors of attempting and succeeding at smoking cessation. Health Educ Res 1991 ; 6(1): 77-86.

19 Hallett R, Sutton SR. Predicting participation and outcome in four workplace smoking intervention programmes. Health Educ Res 1987; 2(3): 257-66.

20 Wilson D, Wakefield M, Owen N, Roberts L. Characteristics of heavy smokers. Prev Med 1992; 21 : 311-9.
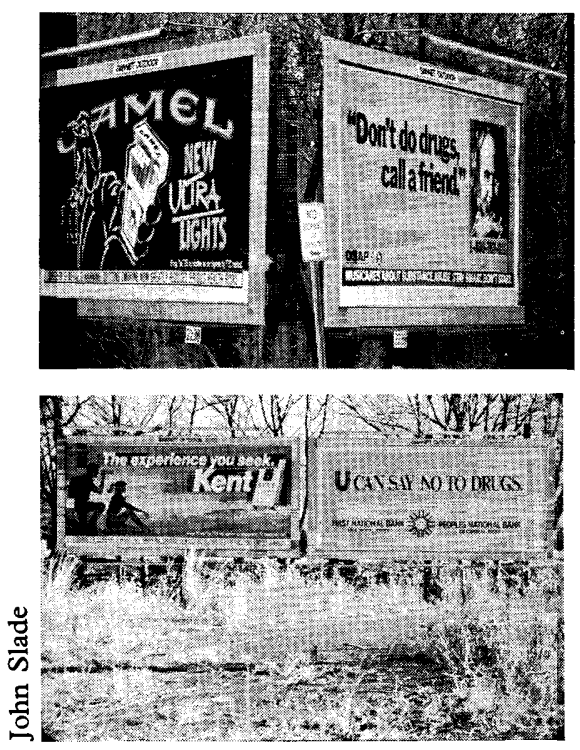

Mixed messages about drugs
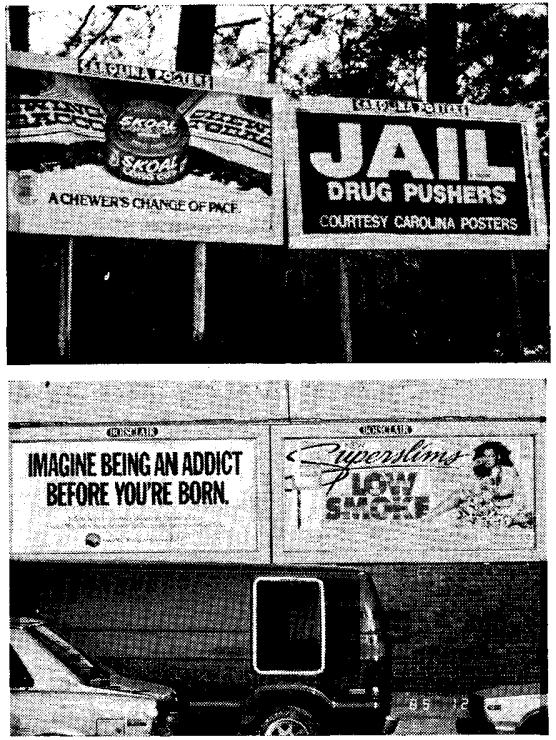